\title{
Técnicas de redução de dados em redes de sensores sem fio tolerantes a atrasos
}

\author{
Israel L. C. Vasconcelos ${ }^{1}$, Andre L. L. Aquino ${ }^{1}$ \\ ${ }^{1}$ Instituto de Computação \\ Universidade Federal de Alagoas - Maceió, AL - Brazil \\ \{israel.vasconcelos, alla\}@laccan.ufal.br
}

\begin{abstract}
This work presents a delay-tolerant sensor network model for environmental applications where a data-aware drop strategy is applied to improve the phenomenon coverage. We design a model for applications that monitor the forest temperature incidence for wildlife observation. The proposed solution modeling comprises of: $i$. Phenomenon generation based on Gaussian random field; ii. Sensing nodes with a mobile sink; iii. Data processing based on a data-aware drop strategy; and iv. Phenomenon reconstruction based on simple kriging interpolation. Besides the satisfactory application of our model, the results show that the performance of our strategy is approximately twice better than traditional ones.
\end{abstract}

Resumo. Este trabalho apresenta um modelo de rede de sensores tolerante a atraso para aplicações de monitoramento ambiental onde uma solução de amostragem sensivel aos dados é utilizada para melhorar a cobertura do fenômeno. $O$ modelo proposto compreende uma aplicação de monitoramento de temperatura em regiões florestais, a implementação consiste em $i$. Simular regiões de interesse; ii. Distribuição dos nós sensores; iii. Realizar amostragem e processamento dos dados; e iv. Reconstruir o fenômeno a partir das amostras. Os resultados obtidos apontaram que a abordagem sensível aos dados é capaz de reconstruir o fenômeno aproximadamente duas vezes mais próximo da realidade em relação às técnicas tradicionais, em todos os cenários avaliados.

\section{Introdução}

No presente trabalho, utilizamos as Redes Tolerantes a Atrasos de Conexões Intermitentes (ICDT-WSNs da expressão em inglês) que corresponde a aplicação do conceito de Redes Tolerantes a Atrasos (DTN) em cenários de Redes de Sensores Sem Fio (WSNs) [Curran and Knox 2008]. Essas redes são utilizadas com sucesso em aplicações de monitoramento de vida selvagem, de locais de difícil acesso, de risco, de desastres naturais, como também de áreas urbanas [Prasad 2015].

Por conta do grande volume de dados gerado nessas redes ICDT-WSNs, recomenda-se o uso de técnicas de redução de dados para manter a confiabilidade e aumentar o tempo de vida da rede, sem comprometer o comportamento das aplicações. As abordagens tradicionais na literatura, para redução de tráfego em ICDT-WSNs, utilizam técnicas não sensíveis aos dados. Por exemplo, o descarte de pacotes por critério aleatório ou ordem de chegada [Li and Bartos 2014]. Tais abordagens comprometem a qualidade dos dados das aplicações. Neste trabalho utilizamos uma redução de tráfego sensível aos 
dados. Nosso objetivo é tornar mais eficiente a utilização do armazenamento disponível mantendo o compromisso de preservar a qualidade dos dados.

Para contornar a restrição da baixa densidade que torna os nós sensores suficientemente distantes ao ponto de comprometer a transmissão sem fio entre eles, típica em redes esparsas, a comunicação entre os nós estáticos é desligada de modo que estes reportam-se apenas a um sorvedouro móvel, que navega pela área coletando os dados de forma oportunista utilizando um único salto para transmissão (single-hop). Na solução utilizada nesse trabalho, a redução é requisitada quando se esgota a memória de armazenamento do sorvedouro. Ela consiste em manipular as amostras coletadas pelos sensores a fim de selecionar as mais significativas, realizando os seguintes passos [Aquino and Nakamura 2009], : i) ordena de forma crescente o conjunto de dados coletados em função dos valores das amostras; ii) divide o conjunto de dados ordenado em dez subconjuntos com intervalos igualmente espaçados, montando um histograma; iii) seleciona as amostras ao redor da mediana de cada subconjunto.

Neste trabalho montamos um arcabouço para modelagem e simulação de experimentos voltados a redução de dados em ICDT-WSNs. Tal arcabouço, define as principais diretrizes para experimentação e validação das soluções propostas. O modelo proposto compreende em: i. Simular regiões de interesse; ii. Distribuição dos nós sensores; iii. Realizar amostragem e processamento dos dados; e iv. Reconstruir o fenômeno a partir das amostras. Os resultados obtidos apontaram que a abordagem sensível aos dados é capaz de reconstruir o fenômeno aproximadamente duas vezes mais próximo da realidade em relação às técnicas tradicionais, em todos os cenários avaliados. Este trabalho gerou as seguintes publicações:

Premiações: Melhor artigo no WTICG-SBRC 2018 [Vasconcelos and Aquino 2018]; $2^{\circ}$ melhor trabalho de IC da Sociedade Brasileira de Matemática Aplicada à Computação 2017, e Excelência Acadêmica no Encontro de IC da UFAL (2014, 2015 e 2016).

Artigo em Periódico: Computer Networks [Vasconcelos et al. 2018] (Qualis-2016 A1, JCR 2.522).

Eventos internacionais: NTMS (Qualis-2016 B1) [Vasconcelos et al. 2015a] e ISCC (Qualis-2016 A2) [Vasconcelos et al. 2015c].

Eventos regionais: ERBASE 2014 (best paper) [Vasconcelos and Aquino 2014] e 2015 [Vasconcelos et al. 2015b].

O restante do trabalho está organizado da seguinte forma: seção 2 apresenta o modelo ICDT-WSNs proposto; seção 3 apresenta a discussão dos resultados dos experimentos; seção 4 apresenta as considerações finais e trabalhos futuros.

\section{Modelo de Aplicação utilizando ICDT-WSN}

Para modelar uma ICDT-WSN, inicialmente, representamos o comportamento ideal dessas redes como

$$
\mathcal{N} \stackrel{P}{\longrightarrow} \mathbf{V}^{*} \stackrel{R}{\longrightarrow} D,
$$

onde $\mathcal{N}$ é o ambiente do qual é observado o fenômeno de interesse $P$, sendo $\mathbf{V}^{*}$ a representação de $P$ no domínio espaçotemporal. Considerando uma observação ideal sobre os dados, sem perdas, é possível definir regras $(R)$ que conduzem a decisões $(D)$

1/http://www.sbmac.org.br/noticias.php?nid=864 
ideais. O conjunto de dados $\mathrm{V}^{*}$ foi modelado como um Campo Gaussiano que é definido como um processo estocástico

$$
\mathbf{V}^{*}(x): x \in d,
$$

onde $d$ representa a dimensão do domínio e $x$ é a variável aleatória.

Como estudo de caso, em nossas simulações, consideramos uma região de interesse simulada na forma de uma matriz $100 \times 100$, representando uma área $10^{4}$ unidades quadradas, sendo seus pontos preenchidos por amostras de uma Gaussiana com média $(\mu)=25$ e variância $(v)=64$ (Campo Gaussiano Aleatório, [Wood and Chan 1994]) e correlacionados espacialmente em função do Modelo de Covariância de Matérn [Diggle and Ribeiro 2007]. Os valores definidos para média e variância representam um comportamento de temperatura, $25^{\circ} \mathrm{C}$, variando $\pm 8^{\circ} \mathrm{C}$. A metodologia apresentada é suficientemente genérica para permitir portar esta aplicação a contextos diversos, nos quais diferentes fenômenos de interesse podem ser avaliados.

Uma vez definidas as características físicas é possível realizar a modelagem dos atributos da rede detalhados a seguir. A atividade dos sensores é modelada como

$$
\mathcal{N} \stackrel{P}{\longrightarrow} \mathbf{V}^{*} \stackrel{S}{\longrightarrow} \mathbf{V} \text {. }
$$

Consideramos um conjunto de sensores $s$, onde $S=\left(S_{1}, \ldots, S_{s}\right)$ e cada sensor reporta uma série de medições $V_{i}$ com $1 \leq i \leq s$ do fenômeno. Assim, o conjunto das medições reportadas por todos os sensores é dado por $\mathbf{V}=\left(V_{1}, \ldots, V_{s}\right)$.

A distribuição dos nós sensores $S$ segue um processo parcialmente aleatório (Simple-Sequential Inhibition - SSI [Baddeley 2007]), onde o controle parcial das posições torna mais realista a modelagem. A Figura 1(a) ilustra a área de interesse gerada a partir do SSI combinada com a distribuição dos nós.

Para delimitar a área pela qual cada nó é responsável por cobrir é construído sobre o campo um diagrama de Voronoi, [Aurenhammer 1991]. Onde as sementes do diagrama serão os nós-sensores e a dominância é a sub-área coberta por cada nó. Esta sub-área é conhecida como Célula de Voronoi. Cada sensor será capaz de medir apenas dados do fenômeno contidos em sua respectiva célula de Voronoi. Este procedimento é ilustrado na Figura 1(b).

Uma vez definido a posição e a área de cobertura de cada nó sensor, modelamos o comportamento da aplicação de amostragem de dados (Figura $1(\mathrm{~d})$, descrito como

$$
\mathcal{N} \stackrel{P}{\longrightarrow} \mathbf{V}^{*} \stackrel{S}{\longrightarrow} \mathbf{V} \stackrel{\Psi}{\longrightarrow} \mathbf{V}^{\prime} \text {. }
$$

Retomando que V representa o conjunto de dados coletados pelos sensores em sua totalidade adjacente à necessidade de redução por diversas limitações de recursos, o sorvedouro utiliza uma técnica amostragem $\Psi$ para reduzir $\mathbf{V}$, resultando no conjunto $\left(\mathbf{V}^{\prime}\right)$.

Conforme explicado anteriormente, este estudo de caso considera uma aplicação onde um nó sorvedouro móvel com movimento aleatório (Random Walk) visita os nós sensores estáticos. Este procedimento é ilustrado na Figura 1(c), A transmissão é realizada de forma oportunista quando houver intersecção entre os raios de alcance dos dispositivos, a amostragem sensível aos dados - $\Psi$ ([Aquino and Nakamura 2009]) é realizada durante a navegação do sorvedouro. 


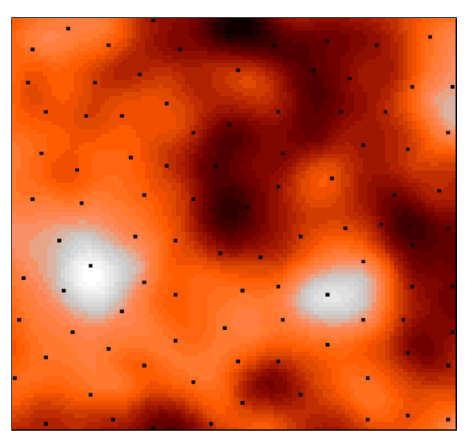

(a) Distribuição dos nós.

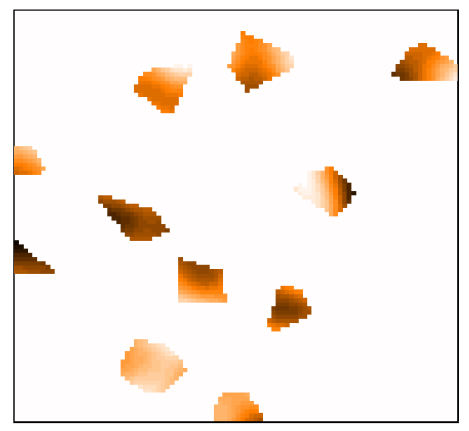

(d) Amostragem dos dados.

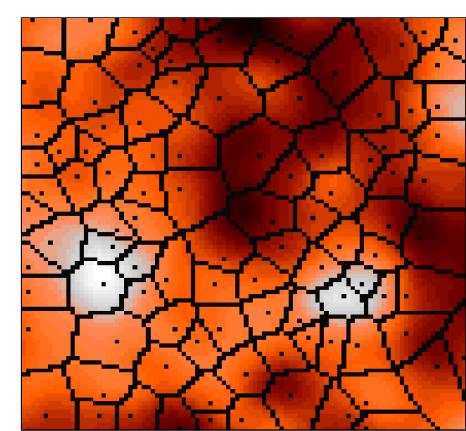

(b) Diagrama de Voronoi.

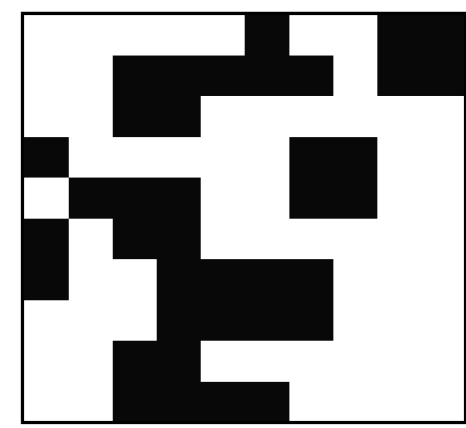

(e) Cobertura das amostras.

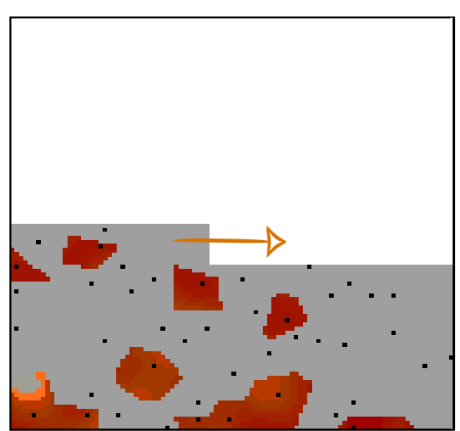

(c) Navegação e coleta.

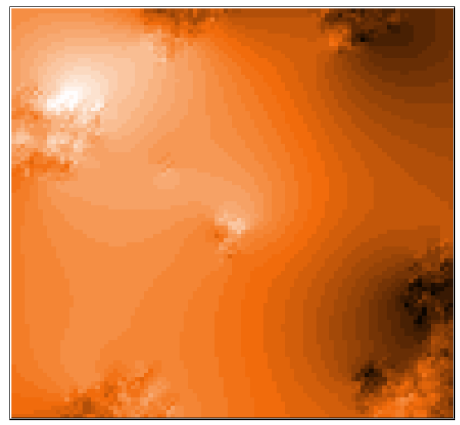

(f) Reconstrução das amostras.

Figura 1. Configuração da Rede, Coleta e Processamento dos Dados.

Após a amostragem de dados é necessária a aplicação de um processo de reconstrução modelado como

$$
\mathbf{V}^{\prime} \stackrel{\omega}{\longrightarrow} \widehat{\mathbf{V}} \stackrel{R}{\longrightarrow} \widehat{D}
$$

Nessa etapa, temos um conjunto de dados reduzidos $V^{\prime}$ que servirá como entrada para executar o processo de reconstrução $\omega$, no nosso caso utilizamos o método de interpolação Kriging Simples, [Hengl 2009]. Após a reconstrução obtemos os dados finais $\widehat{\mathbf{V}}$ utilizados pela aplicação (Figura 1(f)).

Como métrica de avaliação de robustez da nossa técnica, utilizamos o VAER (Valor Absoluto do Erro Relativo [Frery et al. 2010]), definido como

$$
\hat{\epsilon}=\frac{1}{10^{4}} \sum_{i, j=1}^{100}\left|\frac{\mathbf{V}^{*}(i, j)-\widehat{\mathbf{V}}(i, j)}{\mathbf{V}^{*}(i, j)}\right|,
$$

onde $\mathrm{V}^{*}$ é o campo original, simulado inicialmente; $\widehat{\mathrm{V}}$ é a reconstrução do campo a partir das amostras coletadas. Esta expressão é sempre bem definida pois $\mathbf{V}^{*}(i, j) \neq 0$.

Por fim, utilizamos como métrica de avaliação a identificação da cobertura global resultante de cada uma das estratégias. Para isso, uma matriz de $10 \times 10$ foi montado sobre o campo, criando um grid de 100 setores, onde cada setor cobre uma área de $10 \times 10$. Se um setor possui pelo menos um ponto de informação dentro de sua área, este setor é considerado coberto (Figura 1(e)]. A cobertura global é calculada simplesmente a partir da contagem de quantos setores foram cobertos ao final da execução de cada uma das técnicas sob as condições descritas no parágrafo anterior. 


\section{Resultados e Discussões}

Nas simulações, foram executadas 30 replicações independentes do fenômeno para cada cenário avaliado, utilizando semente única. O erro médio é calculado com intervalo de confiança de $95 \%$. Em todos os casos, nós variamos um único parâmetro, fixando todos os outros em seus valores padrão previamente definidos, a lista com os parâmetros e seus respectivos defaults (em negrito) é mostrada na Tabela11, a seguir.

Tabela 1. Parâmetros de Simulação

\begin{tabular}{lc}
\hline Parâmetro & Valores \\
\hline Quantidade de Nós & $\{20,35, \mathbf{5 0}, 100\}$ \\
Tempo de Navegação do sorvedouro Móvel (s) & $\{250,1000,2500, \mathbf{5 0 0 0}, 10000\}$ \\
Capacidade do buffer (Qtd. de Amostras) & $\{500, \mathbf{1 0 0 0}, 1500,2000\}$ \\
\% de Amostragem dos Dados & $\{10 \%, \mathbf{2 5 \%}, 50 \%\}$ \\
Potência do Rádio (dBm) & $\{0,-10,-15, \mathbf{- 2 5}\}$ \\
Velocidade do sorvedouro Móvel (m/s) & $\{\mathbf{2}, 3,4,5,6\}$ \\
Modelo de Navegação do sorvedouro Móvel & Realista (Rota Aleatória) e Ideal (Rota Linear) \\
Modelo de Entrega de Pacotes & Realista (Com Falhas) e Ideal (Sem Perdas) \\
Perturbações ao Fenômeno & Sem Eventos Externos e Com Eventos \\
\hline
\end{tabular}

\subsection{Avaliação do Erro de Reconstrução}

As Figuras 2(a) e 2(b) apresentam a flutuação dos valores de $\hat{\epsilon}$ (Erro de Reconstrução) em função da variação do tamanho do buffer e da quantidade de nós da rede. É possível observar que a abordagem sensível (Data-Aware, linha preta) aos dados apresentou menor erro em todos os cenários, com valores até $42 \%$ inferiores em relação a técnica com melhor desempenho das analisadas, no caso o Random Packet Drop (descarte aleatório de pacotes), linha vermelha. Além do descarte aleatório analisamos as técnicas: Descarte baseado na cobertura global da rede. Descarte do último pacote; Descarte do primeiro pacote; Descarte baseado no tamanho da mensagem; Descarte baseado no número de propagações; e Descarte baseado no tempo de vida; Todas essas técnicas são descritas no survey de Jain et al. [Jain and Chawla 2014]. Especificamente a primeira é uma proposta de Luiz et al. [Luiz et al. 2012]. Além disso, as três primeiras técnicas foram reproduzidas em nossos experimentos anteriores e apresentaram desempenho inferior à abordagem aleatória, por este motivo foram omitidas das análises seguintes. Os resultados dos experimentos supracitados encontram-se reportados nos trabalhos [Vasconcelos et al. 2015a] e [Vasconcelos et al. 2015c].

De forma análoga aos gráficos anteriores (razão para a baixa resolução), as Figuras 2(d), 2(c) e 2(e) relacionam $\hat{\epsilon}$ (Erro de Reconstrução) à variação da Potência do Rádio, Velocidade e Tempo de Navegação do sorvedouro. Novamente, a abordagem proposta apresentou valores de erro inferiores na ordem de 35\%, em média.

Estes experimentos também são conclusivos na definição do setup paramétrico ideal visando economia de recursos e minimização do erro, onde é possível observar a não variação do erro em função da potência do rádio e da velocidade do sorvedouro, dessa forma, podendo definir os menores valores possíveis dentre os testados, economizando bateria e aumentando o intervalo de transmissão entre o sorvedouro e os nós. Relativo ao Tempo de Navegação, os mínimos valores de erro ocorrem a partir dos 2500s, sendo este o período ideal para tal tarefa. 


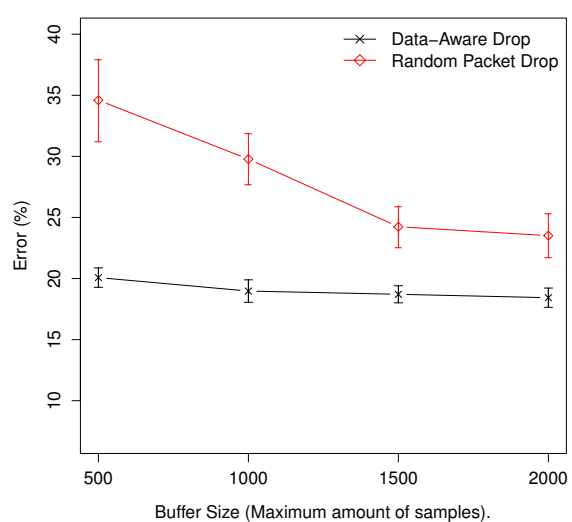

(a) Avaliação do Erro de Reconstrução considerando o tamanho do buffer.

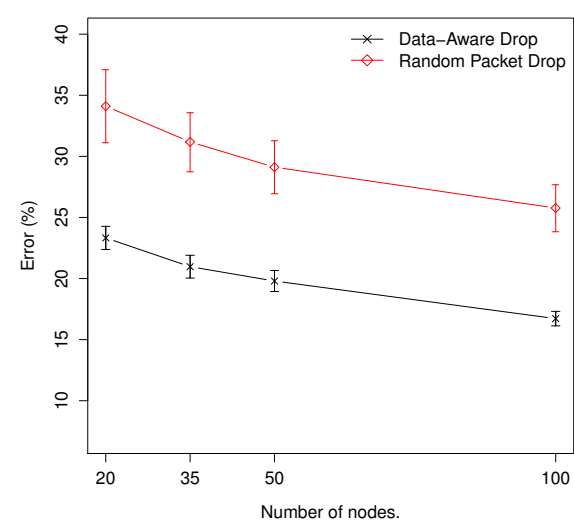

(b) Avaliação do Erro considerando a variação da Densidade da rede.

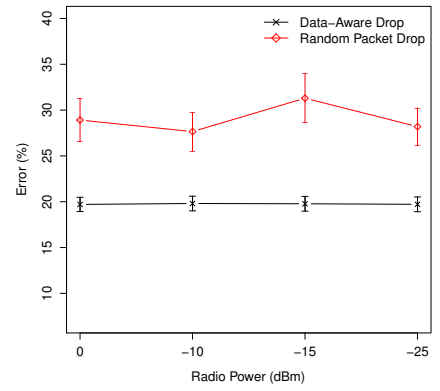

(c) Avaliação do Erro considerando a Potência do Rádio.

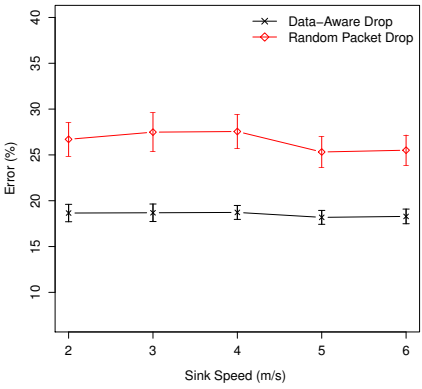

(d) Avaliação do Erro considerando a velocidade de deslocamento do sorvedouro.

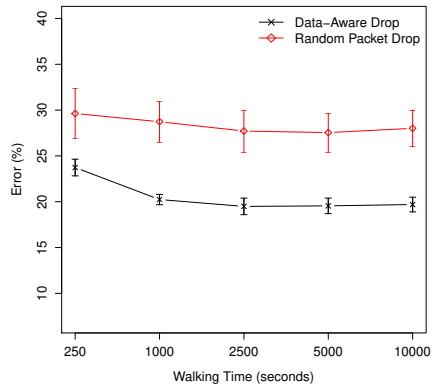

(e) Avaliação do Erro considerando o Tempo de Navegação do sorvedouro.

\section{Figura 2. Comparação do Erro de Reconstrução em função dos Parâmetros de Rede.}

A Figura 3(a) evidencia o quanto a complexidade do modelo de rede interfere nos resultados. O Modelo Ideal não considera a perda de pacotes, a navegação do sorvedouro é ideal, largura de banda infinita e transmissão instantânea de pacotes. Por outro lado, o Modelo Realista considera a perda de pacotes por distância, baixa potência de rádio ou colisão de pacotes, movimento do sorvedouro com rota aleatória e largura de banda limitada.

$\mathrm{Na}$ ausência do Evento Externo, o comportamento das leituras segue os parâmetros definidos de média e variância definidos na Tabela 1 . Em cenários que consideram o evento, as leituras sofrerão variações bruscas em determinadas regiões do campo, adicionando complexidade ao fenômeno para a etapa de reconstrução. Nos resultados é possível observar uma redução no erro na ordem de 75\% para o Modelo Ideal e 37\% para o Modelo Realista.

A Figura 3(b) apresenta um comparativo dos percentuais de amostragem utilizados no algoritmo. Considerando que esta técnica monta um histograma a partir dos dados e realiza a amostragem em uma porcentagem pré definida deste conjunto, este experi- 


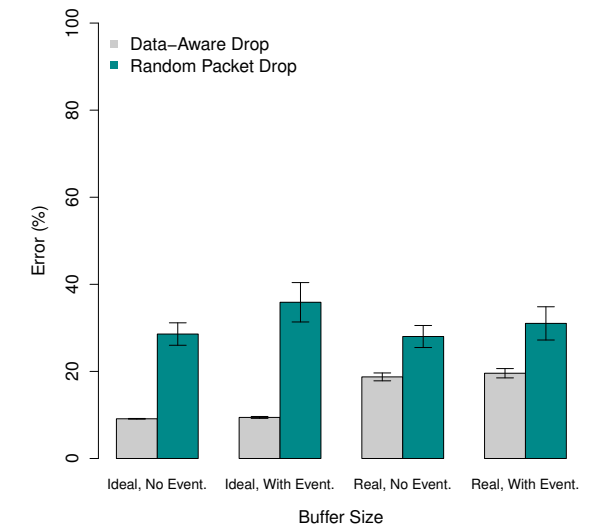

(a) Avaliação do Erro considerando os modelos de rede Ideal e Realista.

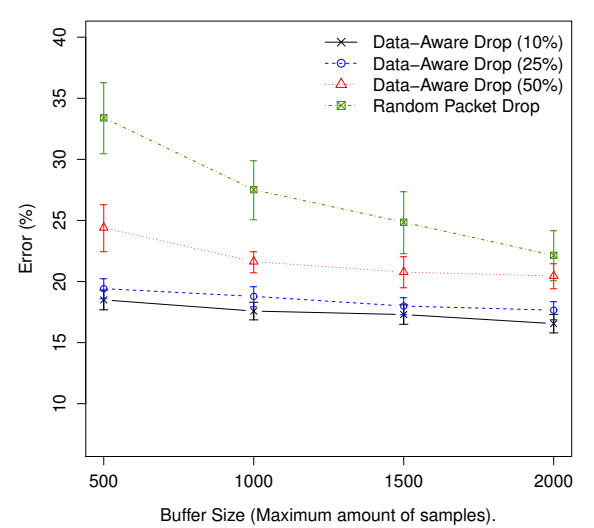

(b) Avaliação do Erro a variação das taxas de amostragem da técnica sensível aos dados.

Figura 3. Avaliação do Erro de Reconstrução considerando a variação da taxa de amostragem e a complexidade do modelo de rede.

mento busca avaliar o impacto deste percentual na cobertura da rede, ou seja, o objetivo é definir o valor ótimo da porcentagem de dados amostrados em relação ao total.

Neste experimento, consideramos como ótimo o percentual de amostragem fixado em $10 \%$ (redução de $90 \%$ ) em virtude dos valores de erro de reconstrução menores em todos os casos mesmo em cenários com tamanho de buffer limitado. O valor padrão para os experimentos (Tabela 1) foi fixado, de forma empírica, em $\mathbf{2 5 \%}$ antes do conhecimento dos resultados da Figura 3(b). Dessa forma, o novo valor definido como mais adequado neste experimento será adotado em avaliações futuras.

Finalmente, observando as Figuras 4(a), 4(b) e 4(c), é possível fazer uma comparação visual entre os resultados das técnicas avaliadas, essa comparação fortalece as conclusões obtidas através da análise dos dados. A Figura 4(a) apresenta o campo original, enquanto a Figura 4(c) apresenta grandes áreas contínuas de com coloração constante resultantes da ausência de dados gerado pelo descarte de pacotes, enquanto o algoritmo de amostragem consegue preservar melhor seus dados (Figura 4(b)).

\subsection{Avaliação da Cobertura Global da Rede}

Nesta seção, será avaliado o desempenho das técnicas sob a métrica apresentada ao final da seção 2. Os parâmetros de rede e níveis de complexidade dos modelos serão avaliados de forma análoga à seção anterior 3.1 .

Os gráficos apresentados na Figura 5 mostram o comportamento das técnicas quando colocadas à prova frente ao aumento de complexidade inerente a ambientes reais, considerando uma quantidade significativamente maior de variáveis de interferência nos parâmetros em estudo.

Nestes gráficos é mostrada uma avaliação comparativa deste comportamento quando confrontado em relação ao modelo ideal, podendo além de visualizar com clareza as limitações deste modelo, também termos uma noção mais acurada do comportamento 


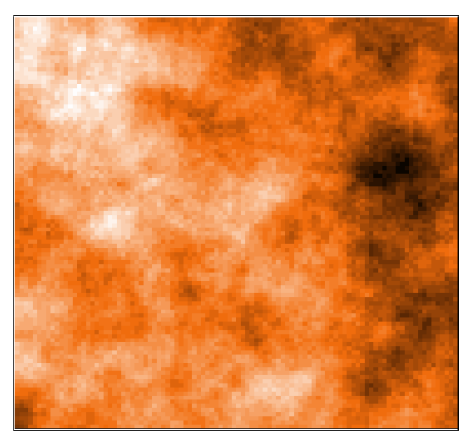

(a) Campo Original

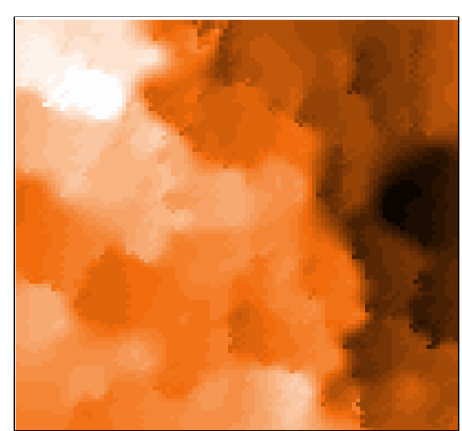

(b) Amostragem Sensível aos Dados - 1000 Amostras

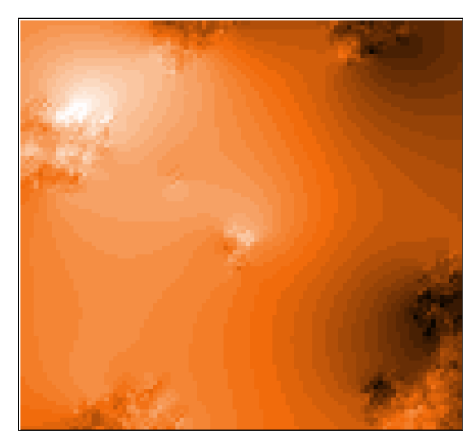

(c) Descarte Aleatório - 1000 Amostras

Figura 4. Comparativo visual entre os resultados das técnicas de amostragem e descarte.

dos algoritmos em situações práticas (não simuladas).

Nas Figuras 5 e 6 as linhas azul e preta correspondem a algoritmo sensível aos dados, onde é possível observar resultados sempre superiores em todos os cenários avaliados, com larga diferença (área de cobertura resultante até $400 \%$ superior) em relação à abordagem clássica (linhas em verde e vermelho).

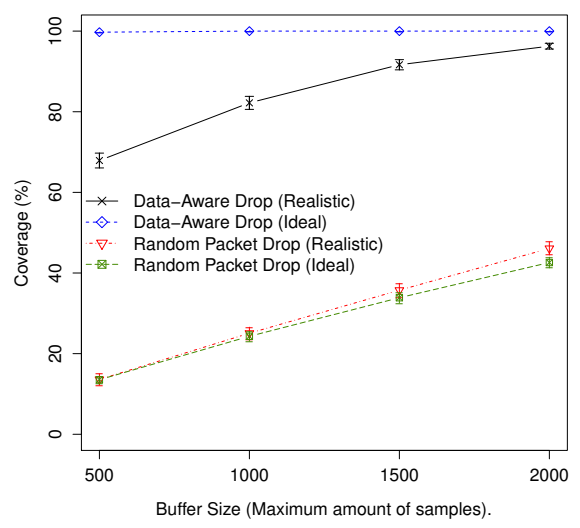

(a) Variação do tamanho do buffer, quantidade de nós fixada em 50.

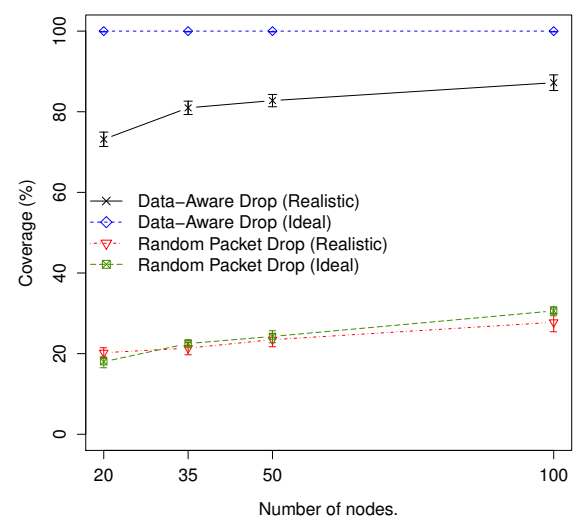

(b) Variação da quantidade de nós, tamanho de buffer fixado em 1000 amostras.

Figura 5. Avaliação de Cobertura considerando tamanho de buffer e densidade da rede, comparação entre os modelos Ideal e Realista.

\section{Conclusão}

Este trabalho apresentou uma solução baseada em amostragem para redução de dados de forma a minimizar perda de informação e otimizar a cobertura global da rede, apresentando resultados satisfatórios nos experimentos e superando o estado da arte. Neste estudo, uma série de fatores inerentes à rede são avaliados, dentre os quais podemos destacar a Densidade da rede, Potência do Raio, Taxa de Amostragem e Transmissão, Tamanho do buffer no sorvedouro, bem como sua Rota, Velocidade e Tempo de deslocamento, Perda de pacotes, Largura de banda e Ocorrência de eventos, por exemplo. 


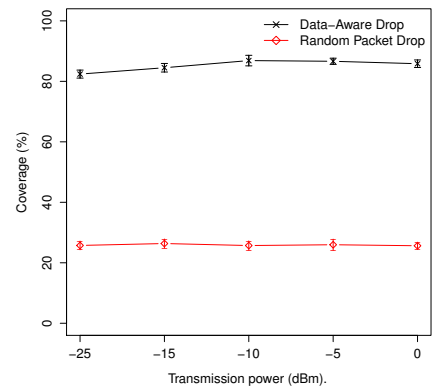

(a) Avaliação do Erro considerando a Potência do Rádio.

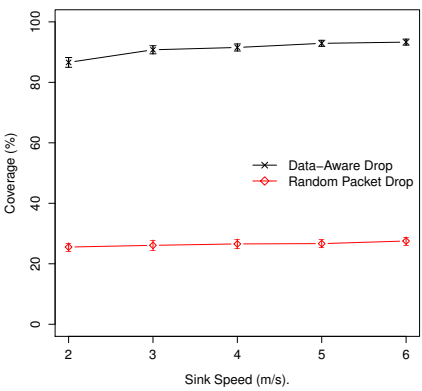

(b) Avaliação do Erro considerando a velocidade de deslocamento do sorvedouro.

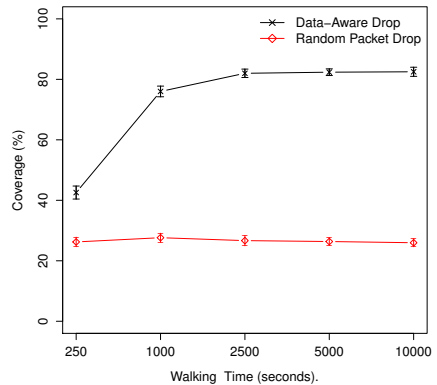

(c) Avaliação do Erro considerando o tempo de navegação do sorvedouro.

Figura 6. Avaliação de Cobertura em função dos Parâmetros de Rede: Potência de Transmissão, Velocidade e Tempo de navegação do sorvedouro Móvel.

Haja vista a sofisticada modelagem computacional e a grande quantidade de cenários levados em conta nos experimentos, os resultados apresentados são conclusivos, consistentes e de abrangência considerável por avaliar uma série de variáveis de dinâmica da rede, mensurando individualmente os impactos de cada uma sob o ponto de vista global. Além disso, traz um conjunto de informações resumidas e de grande utilidade que podem ser aplicadas como diretrizes para a execução de experimentos em ambiente real, poupando tempo, esforços e custos na implementação dos mesmos, já que tem-se em mãos um grande leque de resultados disponíveis.

O projeto completo com guia para reprodução dos experimentos está disponível em repositório aberto para download no link https://github.com/ SensorNet-UFAL/DTN-Model4EnvApplications Finalmente, as perspectivas futuras incluem a incorporação do know-how desenvolvido nesta pesquisa para projeto e experimentação prática, desenvolvimento da solução em novas aplicações, por exemplo subaquáticas, e o aprimoramento constante das soluções redução em estudo.

\section{Referências}

[Aquino and Nakamura 2009] Aquino, A. L. L. and Nakamura, E. (2009). Data centric sensor stream reduction for real-time applications in wireless sensor networks. Sensors, 9:9666-9688.

[Aurenhammer 1991] Aurenhammer, F. (1991). Voronoi diagrams: A survey of a fundamental data structure. ACM Computing Surveys, 23:345-405.

[Baddeley 2007] Baddeley, A. (2007). Spatial point processes and their application. In Weil, W., editor, Stochastic Geometry, volume 1892 of Lecture Notes in Mathematics, pages 1-75. Springer, Berlin.

[Curran and Knox 2008] Curran, K. and Knox, J. (2008). Disruption tolerant networking. Computer and Information Science, 1(1):69-71.

[Diggle and Ribeiro 2007] Diggle, P. J. and Ribeiro, P. J. (2007). Model-based Geostatistics. Springer. 
[Frery et al. 2010] Frery, A. C., Ramos, H. S., Alencar-Neto, J., Nakamura, E., and Loureiro, A. A. F. (2010). Data driven performance evaluation of wireless sensor networks. Sensors, 10(3):2150-2168.

[Hengl 2009] Hengl, T. (2009). A Practical Guide to Geostatistical Mapping.

[Jain and Chawla 2014] Jain, S. and Chawla, M. (2014). Survey of buffer management policies for delay tolerant networks. The Journal of Engineering, 2014(6):7.

[Li and Bartos 2014] Li, Y. and Bartos, R. (2014). A survey of protocols for intermittently connected delay-tolerant wireless sensor networks. Journal of Network and Computer Applications, 41(1):411-423.

[Luiz et al. 2012] Luiz, D. F., Figueiredo, C. M. S., and Nakamura, E. F. (2012). A coverage-based drop-policy in wireless sensor network with disruptive connections. In IEEE Symposium on Computers and Communications.

[Prasad 2015] Prasad, P. (2015). Recent trend in wireless sensor network and its applications: a survey. Sensor Review, 35(2):229-236.

[Vasconcelos and Aquino 2018] Vasconcelos, I. and Aquino, A. L. L. (2018). Redução de dados em redes de sensores sem fio tolerantes a atrasos (best paper). In Anais do XXXVI Simpósio Brasileiro de Redes de Computadores, Workshop de Trabalhos de Graduação.

[Vasconcelos et al. 2018] Vasconcelos, I., Martins, I., Figueiredo, M., and Aquino, A. L. L. (2018). A data sample algorithm applied to wireless sensor network with disruptive connections. Computer Networks, 146(1):1-11.

[Vasconcelos and Aquino 2014] Vasconcelos, I. L. C. and Aquino, A. L. L. (2014). Redução de dados baseada em amostragem para redes de sensores sem fio com tolerância a conexões disruptivas. In Workshop de Trabalhos de Iniciação Científica e Graduação (WTICGBASE).

[Vasconcelos et al. 2015a] Vasconcelos, I. L. C., Lima, D. H. S., Figueiredo, C. M. S., and Aquino, A. L. L. (2015a). A coverage algorithm for intermittently connected delay tolerant wireless sensor networks. In Proceedings of the 7th IFIP International Conference on New Technologies, Mobility and Security.

[Vasconcelos et al. 2015b] Vasconcelos, I. L. C., Lima, D. H. S., Figueiredo, C. M. S., and Aquino, A. L. L. (2015b). Estratégia de redução de dados baseada em amostragem para redes de sensores sem fio tolerantes a atrasos com conexões intermitentes. In $X V$ Escola Regional de Computação Bahia-Alagoas-Sergipe, Workshop de Trabalhos de Iniciação Científica e Graduação (WTICGBASE).

[Vasconcelos et al. 2015c] Vasconcelos, I. L. C., Lima, D. H. S., Figueiredo, C. M. S., and Aquino, A. L. L. (2015c). A sampling algorithm for intermittently connected delay tolerant wireless sensor networks. In Proceedings of the 20th IEEE Symposium on Computers and Communications, .

[Wood and Chan 1994] Wood, A. T. A. and Chan, G. (1994). Simulation of stationary gaussian processes in $[0,1]^{d}$. Journal of Computational and Graphical Statistics, 3(4):409432. 